\title{
ОСОБЕННОСТИ СТОМАТОЛОГИЧЕСКОГО СТАТУСА У ПАЦИЕНТОВ С НАРУШЕНИЕМ СЕРДЕЧНОГО РИТМА НА ФОНЕ ПРИЕМА АНТИКОАГУЛЯНТОВ
}

\section{ORAL HEALTH IN PATIENTS WITH HEART RATE DISORDER TAKING ANTICOAGULANTS}

M. Lomakina

Summary. Demographic data from Russia indicate that a significant shift towards a regressive type of population structure is expected. Statistics show that the geriatric population is growing and life expectancy is projected to increase in the coming years. The elderly suffer from a significant number of comorbidities such as diabetes, hypertension, osteoarthritis, osteoporosis, cardiovascular disease, and cerebrovascular disease. This category of patients requires special dental care and a deeper understanding of the complex interactions between oral diseases and systemic chronic diseases, as well as their pharmacological status. Oral diseases are closely related to systemic diseases, and poor oral health can exacerbate the effects of systemic diseases.

Keywords: oral health, anticoagulant therapy, cardiac arrhythmia.

\author{
Ломакина Мария Витальевна \\ Аспирант, Первый Московский Государственный \\ медицинский университет им. И.М. Сеченова \\ (Сеченовский университет) \\ marusialomakina@yandex.ru
}

Аннотация. Демографические данные России свидетельствуют о том, что ожидается значительный сдвиг в сторону регресивного типа структуры населения. Статистические данные демонстрируют, что гериатрическое население растет, и в ближайшие годы прогнозируется увеличение средней продолжительности жизни. Пожилые люди страдают от значительного количества сопутствующих патологий, таких как диабет, гипертония, остеоартрит, остеопороз, сердечно-сосудистые заболевания и цереброваскулярные заболевания. Данная категория пациентов нуждается в особой стоматологической помощи и более глубоком понимании сложных взаимодействий заболеваний полости рта с системных хронических заболеваний, а также фармокологическим статусом. Заболевания полости рта тесно связаны с системными заболеваниями, а плохое здоровье полости рта может усугубить последствия таких состояний.

Ключевые слова: стоматологический статус, антикоагулятная терапия, нарушение сердечного ритма.

рта и усугубить течение стоматологических заболеваний.

\section{Метолы и принципы исслеАования}

и комплексной проблемой и на него оказывают влияние множество факторов, которые могут служить предикторами таких исходов, как смертность $[1,2]$. Большинство людей старшего возраста имеют сочетанные сопутсвующие патологии, что приводит к риску потери способности к самообслуживанию и зависимости от ухода сторонним лицами, а также к повышенному риску смертности [3-6].

Заболевания сердечно-сосудистой системы занимают лидирующее положение среди показателей как заболеваемости, так смертности и широко распространены среди людей всех возрастных групп. Нарушение здоровья полости рта и нарушение сердечного ритма являются серьезными проблемами; оба состояния увеличивают риск развития кровотечений, что, в свою очередь, увеличивает риск развития тяжелых состояний. Как правило, пациенты, страдающие нарушением ритма, нередко принимают антикоагулянтную терапию, которая в свою очередь может также сказаться на состоянии полости
В рамках научной работы проведено проспективное когортное исследование стоматологического статуса пациентов, получающих антикоагулянтную терапию на фоне нарушения сердечного ритма. В исследовании приняло участие 100 человек, в возрасте от 35 до 75 лет, которое проводилось на базе Института стоматологии ФГАОУ ВО Первый МГМУ им. И.М. Сеченова Минздрава России (Сеченовский Университет).

Критерии включения в исследование:

1. Наличие письменного информированного согласия пациента на участие в исследовании;

2. Возраст более 18 лет;

3. Наличие нарушения сердечного ритма, подтвержденное диагнозом в амбулаторной карте пациента;

4. Наличие назначенной специалистом антикоагулянтной терапии. 
Критерии исключения из исследования:

1. Возраст менее 18 лет

2. Отказ пациента от дальнейшего участия в исследовании;

3. Отсутствие нарушения сердечного ритма, подтвержденного диагнозом в амбулаторной карте пациента;

4. Отсутствие назначенной специалистом антикоагулянтной терапии.

Здоровье полости рта оценивалось с помощью индекс Турески (была проведена бальная оценка: 0 - отсутствие бляшки, 1 - отдельные пятна бляшки в пришеечном районе зуба, 2 - тонкая непрерывная полоса бляшки (до 1 мм) в пришеечной части зуба, 3 - полоса бляшки шире $1 \mathrm{~mm}$, но покрывает менее $1 / 3$ коронки зуба, 4 - бляшка покрывает больше 1/3, но меньше 2/3 коронки зуба, 5 - бляшка покрывает 2/3 коронки зуба или больше), пародонтального индекса кровоточивости десневой борозды в модификации Cowell (критерии оценки: 3 - пациент отмечает кровоточивость при приеме пищи или при чистке зубов, 2 - кровоточивость возникает сразу и в пределах 30 секунд, 1 - кровоточивость возникает не раньше, чем через 30 секунд), пародонтального индекса Рассел, который учитывает тяжесть гингивита, наличие пародонтальных карманов, подвижность зубов, деструкцию костной ткани (была проведена оценка: 8 - выраженная деструкция тканей пародонта, жевательная функция зуба нарушена зуб подвижен, 6 имеется пародонтальный карман, жевательная функция зуба не нарушена, зуб устойчив, 2 - воспаление окружает весь зуб, однако повреждения эпителиального прикрепления нет, 1 - легкий гингивит) и пародонтальным индекс BO3 - CPITN (критерии оценки: 1 балл - обучение индивидуальной гигиене полости рта и контроль за гигиеническим состоянием, 2-3 балла - профессиональная гигиена полости рта и обучение ИГПР, 4 балла - необходимо комплексное лечение заболеваний пародонта).

\section{Результаты}

В рамках исследование приняло участие 100 пациентов со следующим распределением по полу: доля женщин составила $57 \%$ и преобладала над долей мужчин, которая составила 43\%. Возраст большинства пациентов находился в интервале 56-65 лет, что составило 41\%. Наименьшее количество участников (10\%) находились в возрастном интервале от 35 до 45 лет.

У каждого из обследуемых был определен индекс гигиены, характеризующий площадь зубного налёта (индекс Турески). Результаты оценки индекса продемонстрировали, что у 43\% бляшка покрывает 2/3 коронки зуба или больше, 18\% - бляшка покрывает больше
1/3, но меньше $2 / 3$ коронки зуба, $17 \%$ - полоса бляшки шире 1 мм, но покрывает менее $1 / 3$ коронки зуба, $11 \%$ - тонкая непрерывная полоса бляшки (до 1 мм) в пришеечной части зуба, 9\% - отдельные пятна бляшки в пришеечном районе зуба, 2\% - отсутствие бляшки.

При оценке пародонтального индекса кровоточивости десневой борозды (SBI Muhlemann u Son, 1971) в модификации Cowell (1975) было выявлено: 70\% пациентов отмечали кровоточивость при приеме пищи или при чистке зубов, 20\% - кровоточивость возникала сразу и в пределах 30 секунд и 10\% отмечали, что кровоточивость возникала не раньше, чем через 30 секунд.

В результате оценки парадонтального индекса Рассел (PI Russel, 1956) было обнаружено следующее распредление пациентов по стадиями заболевания: 50\% пациентов был диагностирован парадонтит I стадии заболевания, что соответсвует легкому гингивиту или воспалению, которое окружает весь зуб, однако повреждения эпителиального прикрепления нет; 40\% имели парадонтит II стадия (средняя степень), что соответсвует наличию пародонтального кармана и отсутствию нарушения жевательной функции зуба, зуб устойчив; 10\% страдают от парадонтита III стадия (тяжелая степень) что соответсвует выраженной деструкции тканей пародонта и нарушению жевательной функции зуба, зуб подвижен. Вместе с тем была проведена оценка кровоточивости десен при помощи специального градуированного пародонтального зонда, с утолщением на конце, оценивалось состояние десневой борозды и пародонта в области 10 зубов. В результате проведенного обследования было выявлено, что кровоточивость после зондирования и легкое воспаление десневого края наблюдалось у $10 \%$, у $40 \%$ пациентов было обнаружено над- и поддесневой камень, а также десневая бороздка - до 3 мм, также патологический зубодесневой карман 4-5 мм встречался у $40 \%$ и $10 \%$ пациентов имели патологический зубодесневой карман 6 мм и более.

В целях определения потребности в лечении парадонта пациаентам проводили оценку пародонтального индекса ВО3 - CPITN. Таким образом более половины обследованных пациентов нуждались в комплексном лечении заболеваний пародонта, 39\% требовалась профессиональная гигиена полости рта и обучение ИГПР и только у $10 \%$ была необходимость в обучении индивидуальной гигиене полости рта и контроль за гигиеническим состоянием.

\section{Зак^ючение}

Проведенное исследование продемонстрировало, что у пациентов с нарушением сердечного ритма, принимающих антикоагулянты, неудовлетворительный стома- 
тологический статус, требующий комплексного лечения и профилактики. Как правило, пациенты страдают от парадонтита средней или тяжелой стадии, имеют кровоточивость десен при приеме пищи или при чистке зубов. Повышенная расположенность к кровоточивости десён, может быть, в том числе обусловлена приёмом антикоагулятной терапии и состояние ротовой полости может усугубляться. В связи с вышеизложенным стоит учитывать особенности фармокологического и стоматологического статусов при разработке программ лечения данной категории пациентов. Вместе с тем, более половины обследуемых пациентов имеют зубной налет высокой степени выраженности, а также патологический зубодесневой карман, что требуется учитывать при разработке адресных программ лечения. Таким образом, ре- зультаты анализа стоматологического статуса пациентов позволяют сделать вывод о необходимости разработки протокола ведения стоматологического пациента с нарушением ритма сердца, принимающих антокогулятную терапию с учётом особенностей течения стоматологических заболеваний и данной категории пациентов.

\section{Финансирование}

Исследование не имело спонсорской поддержки.

\section{КонфАикт интересов}

Авторы заявляют об отсутствии конфликта интересов.

\section{ЛИТЕРАТУРА}

1. Awano S., Ansai T., Takata Y., et al. Oral health and mortality risk from pneumonia in the elderly. J Dent Res. 2008;87:334-339.

2. Cano C., Samper-Ternent R., Al Snih S., Markides K., Ottenbacher K.J. Frailty and cognitive impairment as predictors of mortality in older Mexican Americans. J Nutr Health Aging. 2012;16:142-147.

3. Beard J.R., Officer A., de Carvalho I.A., et al. The World report on ageing and health: a policy framework for healthy ageing. Lancet. 2016;387:2145-2154.

4. Ortega 0. , Sakwinska 0. , Combremont $S$., et al. High prevalence of colonization of oral cavity by respiratory pathogens in frail older patients with oropharyngeal dysphagia. Neurogastroenterol Motil. 2015;27:1804-1816.

5. Norderyd 0., Koch G., Papias A., et al. Oral health of individuals aged 3-80 years in Jonkoping, Sweden during 40 years (1973-2013). Swed Dent J. 2015;39:69-86

6. Andersson P., Renvert S., Sjogren P., Zimmerman M. Dental status in nursing home residents with domiciliary dental care in Sweden. Community Dent Health. 2017; $34: 203-207$

(c) Ломакина Мария Витальевна ( marusialomakina@yandex.ru ).

Журнал «Современная наука: актуальные проблемы теории и практики»

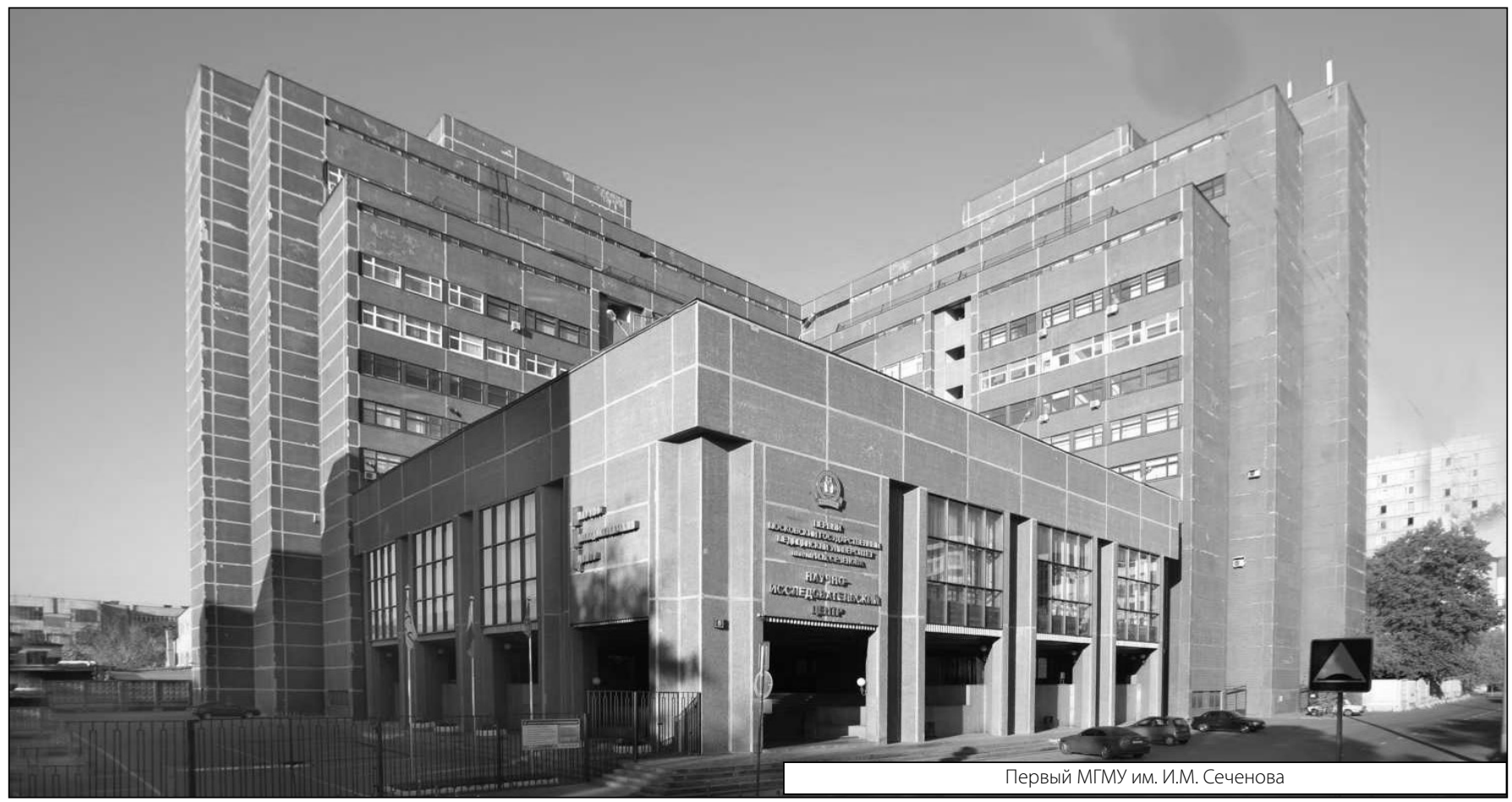

